\title{
Visual assessment of infants: vernier targets for the Catford drum
}

Bryan Hopkisson, Pamela Arnold, Barbara Billingham, Marilyn McGarrigle, Philip Entwistle

\begin{abstract}
Targets comprising a horizontal black line 5 thick offset by $1^{\prime}$ 'were printed on strips to stick to the drums of the Catford Visual Acuity Apparatus. The 'vernier' targets so produced corresponded to the different sizes of Snellen letters from 6/6 to 2/60 when presented at 50 $\mathrm{cm}$. Twenty-five children between the ages of 3 and 12 years with known amblyopia (mostly strabismic) were tested in a double blind trial to compare the visibility of the vernier targets with subjective Snellen acuity. All vernier results, both for better and amblyopic eye, were within one line of Snellen acuity. One hundred and twenty normal preverbal infants with normal eyes under the age of $2 \frac{1}{2}$ years were tested with the vernier strips. Normal infants under the age of 6 months recorded a vision of 6/60-2/60; normal infants aged 6 to 12 months recorded $6 / 24-6 / 36$, and infants between the ages of 1 and $2 \frac{1}{2}$ years recorded 6/12-6/18.
\end{abstract}

Catford and Oliver ${ }^{1}$ described an instrument for the objective determination of visual acuity. It consisted of a motor driven drum which could display black dots of various sizes in oscillatory motion against a white background. Acuities were determined by finding the smallest dot which could be fixed and followed by the patient. The drum dot targets were criticised because they subtended five' of arc and were contrast targets, testing merely visibility, thereby giving a marked overestimate of acuity. ${ }^{2}$ The drum method was also criticised because it used a moving target which was presumed to have a synergistic effect by simultaneously exciting a new area of retina while leaving an inhibitory area. $^{3}$

The forced-choice preferential looking (FPL) method is also used as a means of estimating acuity and other visual detection performance in infants. $^{48}$ However, there is often a poor relationship between Snellen letter acuity and measures of resolution such as grating acuity. ${ }^{910}$ Teller acuity cards do not reliably detect

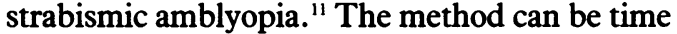
consuming, variable in older infants, and difficult to interpret in the clinical situation.

Shimojo et $a l^{12}$ described a motor sound display to measure vernier acuity. In this display a pair of striped patterns was presented, one of which contained horizontal vernier offsets on its edges. The displacement of the vernier offsets gave the impression of intermittent motion of a target which was defined by these offsets. The motion was perceived only when the vernier offsets were detected. Vernier acuity, defined as the inverse of the smallest detectable misalignment of edges, gives a resolving power of the order of $4^{\prime \prime}$ of arc for the contour break and $0.5^{\prime \prime}$ of arc for the line. ${ }^{13}$ It has therefore been termed a type of hyperacuity, ${ }^{14}$ which may be considered an outcome of central visual processing.

Atkinson $e t a l^{2}$ stated that in principle they believe the use of an ocular following response to repetitive movement of a discrete target as proposed by Catford and Oliver is a robust method. It offers one of the best chances of rapid and reliable acuity assessment in children aged between 6 months and $2 \frac{1}{2}$ years if a better target could be found. Since vernier acuity is known to be less than grating acuity in neonates ${ }^{12}$ and in strabismic amblyopes, ${ }^{15-17}$ we developed targets with vernier offsets for attachment to the Catford machine so that we might compare the visibility of them with subjective Snellen acuity for a group of amblyopic children whose acuities could be reliably subjectively tested. We also recorded the vernier vision of 120 normal preverbal infants with the same vernier targets.

\section{Apparatus}

A black horizontal line on a white background moving horizontally is not perceived to move if the ends of the line are concealed. If the line has a vernier offset and the offset is perceived, the eye may fix and follow it. If targets of decreasing
Eye Department, Northampton General Hospital B Hopkisson P Arnold B Billingham M McGarrigle

Nene College, Northampton P Entwistle

Correspondence to: B Hopkisson, FRCS, Eye Department, Northampto General Hospital, Northampton NN1 5BD. Accepted for publication 26 October 1990
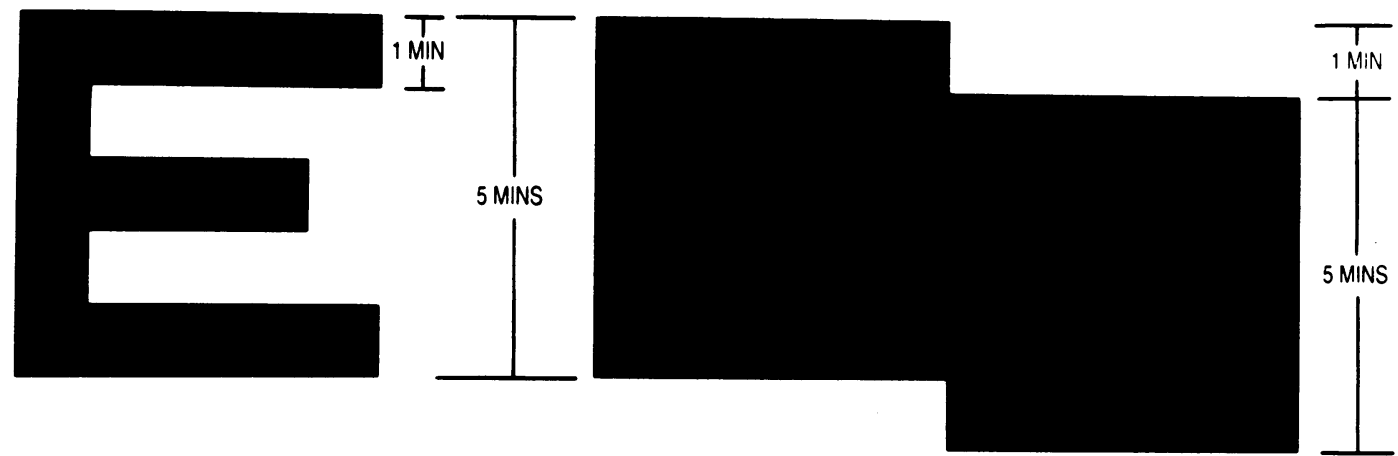

Figure 1 Snellen and vernier targets. 


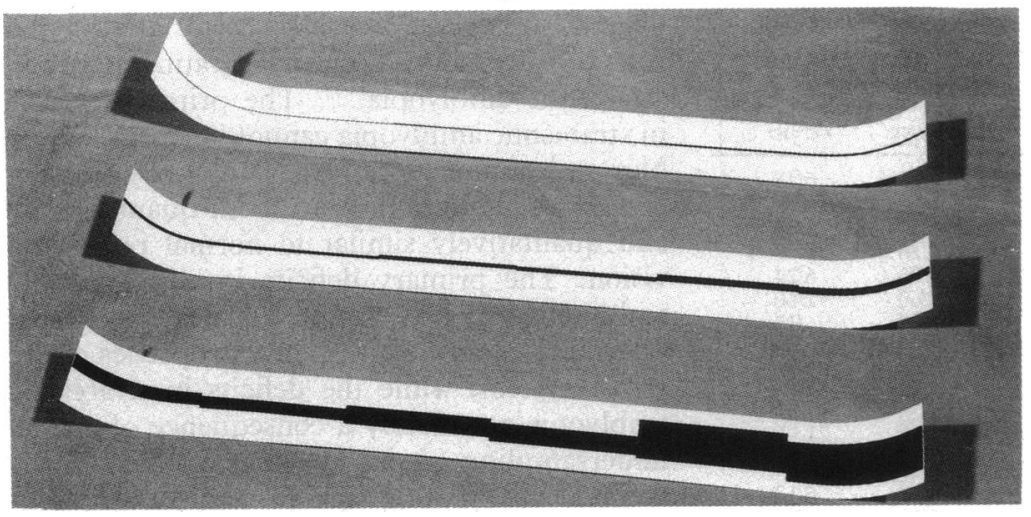

Figure 2 'Vernier' strips. size are presented, they may be fixed and followed until they are too small to be seen. The smallest target fixed and followed is a measure of some form of vision.

We therefore printed on card strips a line with a vernier offset corresponding to the different sizes of the Snellen letters from $6 / 6$ to $2 / 60$ for presentation at $50 \mathrm{~cm}$. To correspond with Snellen letters the horizontal black line was 5' thick offset by $\mathbf{l}^{\prime}$ (Fig 1). The ends of the target lines are concealed by the vertical sides of the viewing aperture in the Catford apparatus screen if only three targets are printed on each strip, the full range of $6 / 60$ to $2 / 60$ requiring therefore three strips:

Strip 1 6/6 6/9 6/12.

Strip $26 / 186 / 246 / 36$.

Strip 3 6/60 4/60 2/60 (Fig 2).

The strips were stuck to Catford drums. Plain white card strips were stuck to the apparatus screen to narrow vertically the viewing aperture, so that only the line and offset were visible to the subject, and the moving edges of the drum were concealed even if the screen was inadvertently tilted in a vertical direction (Fig 3).

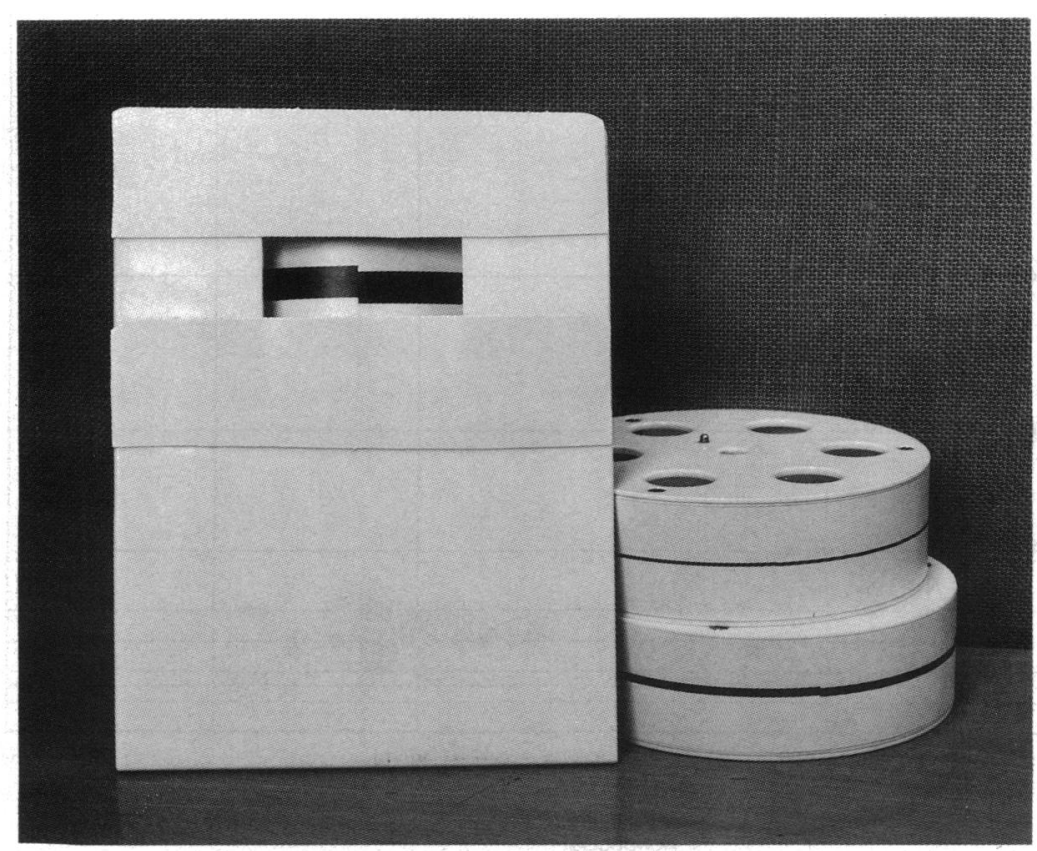

Figure 3 Catford apparatus with 'vernier' strips attached.
Subjects, method, and results

Twenty-five children between the ages of 3 and 12 years with known amblyopia were selected from routine orthoptic clinics by one orthoptist. Another orthoptist, holding the apparatus $50 \mathrm{~cm}$ from the subject's eye (the motor operating at speed setting 2) recorded as the vernier acuity the smallest target fixed and followed, starting with the larger targets and presenting smaller and smaller targets until no following movements were observed. Only the smooth pursuit movement of following the offset was recorded; the rapid saccadic movements observed when the offset is temporarily lost to perception and the subject searches for it again were ignored. In the same room under the same lighting conditions, a third orthoptist recorded the Snellen acuity at $6 \mathrm{~m}$. Neither of the recording orthoptists had knowledge of previous acuities nor of the other orthoptist's results.

All vernier results were within one line of Snellen acuity; not one amblyope was missed, and no hyperacuity values were recorded. Most of the children tested had strabismic amblyopia, but one had anisometropia, one a microtropia, one unilateral aphakia and one congenital nystagmus in addition to strabismic amblyopia (Table 1). Further statistical analysis of these results is difficult. One cannot statistically analyse all 50 eyes because of the lack of independence of the data from amblyopic and fellow eye. ${ }^{18}$

We recorded vernier visions on 120 preverbal infants under the age of $2 \frac{1}{2}$ years who attended our routine orthoptic clinics. These infants, after the test, were all found to be normal optically, orthoptically, and ophthalmologically.

It can be seen that babies in the early months of life have a vernier vision between $2 / 60$ and $6 /$ 60 . This vision rapidly improves to $6 / 36-6 / 24$ by 6 months of age and then levels out around 6/18$6 / 12$ after 1 year (Fig 4).

\section{Discussion}

The assessment of visual acuity in all children under the age of $2^{1 / 2}$ years in the clinical situation has always been a problem. In the young, from whom subjective answers are unobtainable, objective measures must be used. Visibility has been measured by Catford dots and Stycar balls; resolution has been measured by preferential looking gratings and checkerboard visual evoked responses, while vernier acuity has been measured in motor display systems in laboratories. None of these methods has proved ideal and comprehensive in the clinical situation. It is extremely difficult, perhaps impossible, to assess recognition clinically in preverbal infants. A small child has a very short span of attention and rapidly becomes bored. When assessing a young child by behavioural methods it is dangerous to assume that a lack of behavioural response to a target means that the target is not perceived or resolved. Any indirect behavioural method of assessment poses the same problem of interpreting a negative result.

One of the main causes of reduced vision in infants and children is amblyopia. It is not yet clear precisely what is the visual difficulty in 
Table 1 Comparison of acuities. Vermier strip and Snellen in 25 amblyopic children

\begin{tabular}{|c|c|c|c|c|c|c|}
\hline \multirow[t]{2}{*}{ Subject } & \multirow[t]{2}{*}{ Age (years) } & \multirow[t]{2}{*}{ Diagnosis } & \multicolumn{2}{|c|}{ Better eye } & \multicolumn{2}{|c|}{ Amblyopic eye } \\
\hline & & & Snellen & Vermier & Snellen & Vernier \\
\hline $\begin{array}{l}1 \\
2 \\
3 \\
4 \\
5 \\
5 \\
6 \\
7 \\
8\end{array}$ & $\begin{array}{r}11 \\
6 \\
5 \\
4 \\
4 \\
6 \\
12 \\
5\end{array}$ & $\begin{array}{l}\text { LDS } \\
\text { RCS } \\
\text { RCS } \\
\text { LCS } \\
\text { LCS } \\
\text { LCS } \\
\text { RCS } \\
\text { RCS Congenital }\end{array}$ & $\begin{array}{l}6 / 6 \\
6 / 6 \\
6 / 6 \\
6 / 9 \\
6 / 6 \\
6 / 9 \\
6 / 6 \\
6 / 18\end{array}$ & $\begin{array}{l}6 / 6 \\
6 / 6 \\
6 / 6 \\
6 / 12 \\
6 / 9 \\
6 / 12 \\
6 / 6 \\
6 / 18\end{array}$ & $\begin{array}{l}6 / 18 \\
6 / 36 \\
6 / 24 \\
6 / 36 \\
6 / 36 \\
4 / 60 \\
6 / 18 \\
2 / 60\end{array}$ & $\begin{array}{l}6 / 18 \\
6 / 60 \\
6 / 24 \\
6 / 60 \\
6 / 24 \\
2 / 60 \\
6 / 18 \\
2 / 60\end{array}$ \\
\hline $\begin{array}{r}9 \\
10 \\
11 \\
12 \\
13 \\
14 \\
15 \\
16 \\
17 \\
18 \\
19 \\
20 \\
21 \\
22 \\
23 \\
24 \\
25\end{array}$ & $\begin{array}{l}6 \\
5 \\
6 \\
7 \\
6 \\
6 \\
5 \\
4 \\
6 \\
4 \\
6 \\
6 \\
5 \\
3 \\
5 \\
8 \\
3\end{array}$ & $\begin{array}{l}\text { Left aphakia c CL } \\
\text { LCS } \\
\text { RCS } \\
\text { LCS } \\
\text { LCS } \\
\text { RCS } \\
\text { Left microtropia } \\
\text { Left anisometropia } \\
\text { LCS } \\
\text { LCS L/R } \\
\text { LCS } \\
\text { LCS } \\
\text { LCS } \\
\text { RCS } \\
\text { RCS } \\
\text { LCS } \\
\text { RCS }\end{array}$ & $\begin{array}{l}6 / 6 \\
6 / 6 \\
6 / 9 \\
6 / 6 \\
6 / 6 \\
6 / 6 \\
6 / 9 \\
6 / 9 \\
6 / 9 \\
6 / 6 \\
6 / 6 \\
6 / 6 \\
6 / 6 \\
6 / 12 \\
6 / 6 \\
6 / 6 \\
6 / 9\end{array}$ & $\begin{array}{l}6 / 6 \\
6 / 6 \\
6 / 12 \\
6 / 9 \\
6 / 9 \\
6 / 6 \\
6 / 9 \\
6 / 9 \\
6 / 9 \\
6 / 9 \\
6 / 9 \\
6 / 9 \\
6 / 9 \\
6 / 18 \\
6 / 9 \\
6 / 9 \\
6 / 9\end{array}$ & $\begin{array}{r}6 / 36 \\
<1 / 60 \\
6 / 18 \\
6 / 18 \\
6 / 18 \\
6 / 18 \\
6 / 18 \\
6 / 60 \\
6 / 18 \\
2 / 60 \\
6 / 12 \\
6 / 36 \\
6 / 18 \\
6 / 60 \\
6 / 24 \\
6 / 24 \\
6 / 18\end{array}$ & $\begin{array}{r}6 / 36 \\
<2 / 60 \\
6 / 24 \\
6 / 24 \\
6 / 12 \\
6 / 24 \\
6 / 18 \\
6 / 36 \\
6 / 18 \\
<2 / 60 \\
6 / 12 \\
6 / 24 \\
6 / 24 \\
6 / 36 \\
6 / 18 \\
6 / 18 \\
6 / 18\end{array}$ \\
\hline
\end{tabular}

LDS=left divergent squint. $\mathrm{LCS}=$ left convergent squint. $\mathrm{RCS}=$ right convergent squint. c $C L=$ with contact lens. $L / R=$ left over right.

amblyopia, but there is considerable evidence that it is not simply blurring of the image. ${ }^{91017}$ Strabismic amblyopes and neonates both behave similarly when faced with vernier targets. ${ }^{12}{ }^{15-17}$

Grating acuity may depend on the smallest size of receptor field that shows functionally effective contrast sensitivity. ${ }^{71}$ Vernier acuity requires detection of offsets and may depend more on the density of receptor fields than on the size of them..$^{20}$ It deteriorates two to three times faster than grating acuity in the normal retinal peri- phery as a function of retinal eccentricity, ${ }^{172}$ and it is also degraded more than grating acuity in strabismic amblyopia. ${ }^{15-17}$ The primary deficits in strabismic amblyopia cannot be mimicked by blur and cannot be explained solely by filtering properties. Rather they are both quantitatively and qualitatively similar to normal peripheral vision. The primary deficits in anisometropic amblyopia can be accounted for by the spatial filtering and contrast response properties of the visual system, while the deficits in strabismic amblyopia are mainly a consequence of spatial undersampling as in neonatal vision. ${ }^{17}$ Since vernier and grating acuities reflect different aspects of visual sampling and early processing, the comparison between them within individual infants may serve as a significant critical test during the first year of life. ${ }^{20}$ Because of the undersampling concept perhaps our vernier type targets may be more clinically useful in early infancy and strabismic amblyopia than preferential looking gratings.

Our targets cannot possibly be measuring true vernier hyperacuity, as no gross hyperacuity values are obtained in comparison with Snellen acuity in amblyopic children. There appears to be no overestimate of vision produced by our moving targets. Indeed it has been shown that there is no significant difference between visual acuities with static and phase alternated targets. ${ }^{22}$

The drum method of vision testing has been recognised as offering one of the best chances of rapid and reliable assessment of vision in small children if a better target could be devised. We know that the Catford apparatus is robust and has stood the test of time in mechanical reliability.

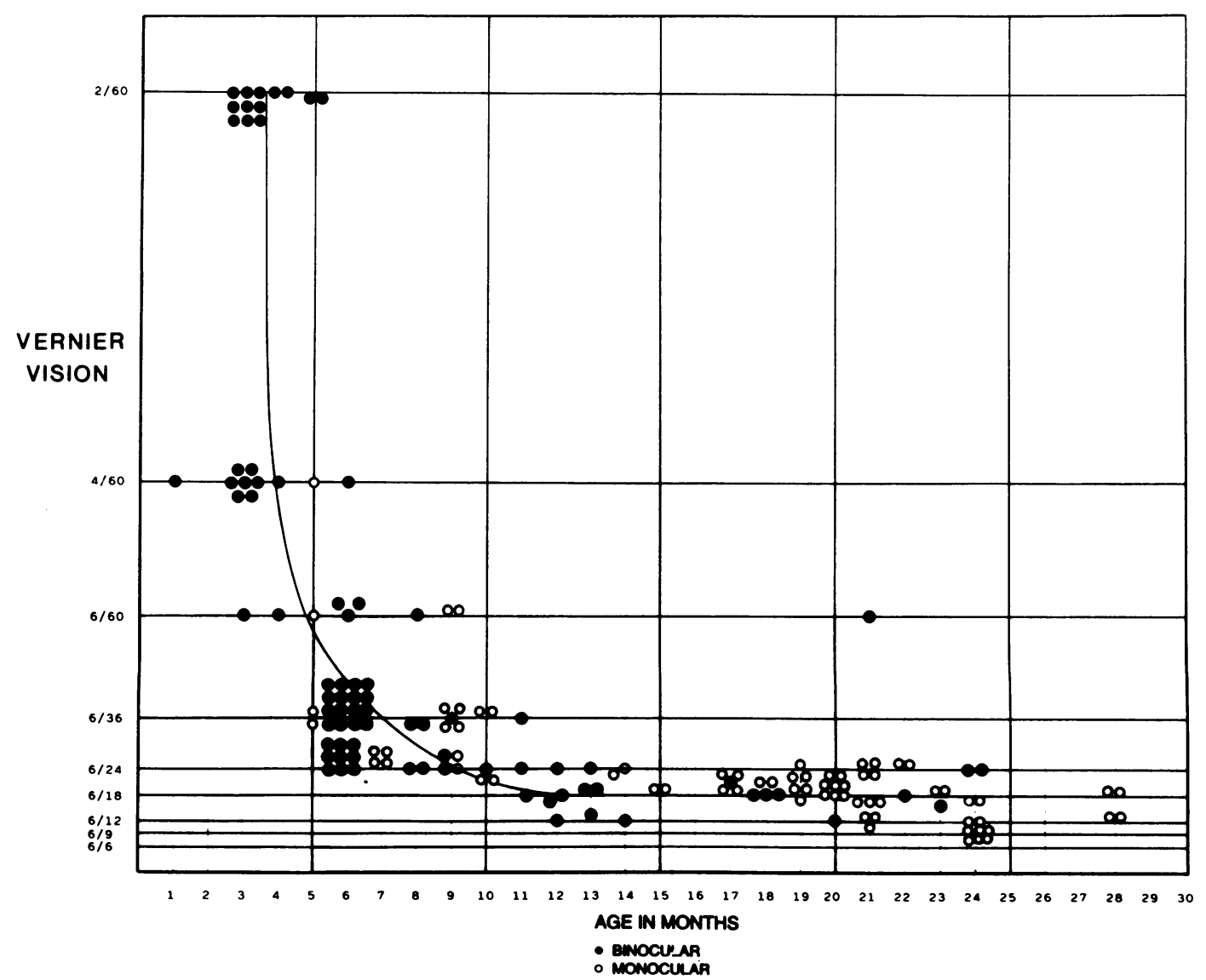

Figure 4120 normal infants: development of 'vernier' vision. 
We know that most orthoptists are familiar with the apparatus and find it simple, quick, and easy to use in the clinical situation. We believe that we have developed a target for the Catford drum which gives a clinically good and useful visual value in young children and indeed in older children who cannot be formally tested by other quick, easy methods in the clinical situation. The strips are cheap and replaceable when soiled; they are easily attached to the drums by double sided sticky tape or glue.

We have found a knowledge of our vernier vision in normal babies, in babies with squint, in anisometropia and some pathological conditions is clinically useful. We can certainly record the improvement in vision in the amblyopic eye of preverbal children after occlusive therapy, and we are confidently able to discharge from followup children with pseudosquint who have been found to have equally good vision in each eye much earlier than previously.

We are sure that there will be exceptions and difficult cases to assess with our targets, especially some cases with ocular motility problems, but we have certainly been able to record accurate visions of some children with congenital nystagmus.

We do not pretend to understand fully the physiological reasons for our targets giving a clinically reasonable correlation with Snellen targets, but we believe this method of visual assessment warrants further investigation to establish the true extent of its potential.

We thank Mr G V Catford for his help and encouragement in this project.
1 Catford GV, Oliver A. Development of visual acuity. Arch Dis Child 1973; 48: 47-50.

2 Atkinson J, Braddick O, Pimm-Smith E, Ayling L, Sawyer R. Does the Catford drum give an accurate assessment of acuity? Br F Ophthalmol 1981; 65: 652-6.

3 Khan SG, Chen KF, Frenkel M: Subjective and objective visual acuity testing techniques. Arch Ophthalmol 1976; 94: 2086-91.

4 Teller DY, Morse R, Borton R, Regal D. Visual acuity for vertical and diagonal gratings in human infants. Vision Res 1974; 14: 1433-9.

5 Teller DY. The forced-choice preferential looking procedure: a psychophysical technique for use with human infants. a psychophysical technique for use
Infant Behav Dev 1979; 2: 135-53.

6 Atkinson J, Braddick O, Moar K. Development of contrast sensitivity over the first 3 months of life in the human infant. sensitivity over the first 3 mon
Vision Res 1977; 17: 1037-44.

7 Banks MS, Salapatek P. Acuity and contrast sensitivity in 1-, 2-, and 3-month-old human infants. Invest Ophthalmol Vis Sci 1978; 17: 361-5

8 Gwiazda J, Brill S, Mohindra I, Held R. Infant visual acuity and its meridional variation. Vision Res 1978; 18: 1557-64.

9 Hess RF, Cambell FW, 'Greenhalgh T. On the nature of the neural abnormality in human amblyopia; neural aberrations and neural sensitivity loss. Pflugers Arch 1978; 377: 201-7.

10 Hess RF, Jenkins S. Amblyopia cannot be explained by considering only detection thresholds. Perception 1980; 9: 569-76.

11 Katz B, Sireteanu R. Teller acuity card test. Klin Monatsbl Augenheilkd 1989; 195: 17-22.

12 Shimojo S, Birch EE, Gwiazda J, Held R. Development of vernier acuity in infants. Vision Res 1984; 24: 721-8.

13 Davson H. Physiology of the eye.2nd ed. London: Churchill 1963: 168.

14 Westheimer G. The spatial sense of the eye. Invest Ophthalmol Vis Sci 1979; 18: 893-912.

15 Levi DM, Klein SA. Hyperacuity and amblyopia. Nature 1982; 298: 268-70.

16 Levi DM, Klein SA. Differences in vernier discrimination for gratings between strabismic and anisometropic amblyopes. Invest Ophthalmol Vis $S c i$ 1982; 23: 398-407.

17 Levi DM, Klein SA. Vernier acuity, crowding and amblyopia. Vision Res 1985; 25: 979-91.

18 Ray WA, O'Day DM. Statistical analysis of multi-eye data in ophthalmic research Invest Ophthalmol Vis Sci 1985; 26: ophthalmic

19 Atkinson J, Braddick O, Braddick F. Acuity and contrast sensitivity of infant vision. Nature $1974 ; 247: 403$

20 Shimojo $S$, Held $\mathbf{R}$. Vernier acuity is less than grating acuity in 2- and 3-month-olds. Vision Res 1987; 27: 77-86.

21 Westheimer G. The spatial grain of the perifoveal visual field. Vision Res 1982; 22: 157-62.

22 Dobson V, Teller DY, Belgum J. Visual acuity in human infants assessed with stationary stripes and phase-alternated checkerboards. Vision Res 1978; 18: 1233-8. 